\title{
Effectiveness of Two Exercise Training Programs in Patients with Chronic Obstructive Pulmonary Disease
}

\author{
Angela Maria Pereira ${ }^{1,2,3,}$, Ernesto Pereira $^{3}$, Sónia Vicente ${ }^{1,2}$, Helena Santa-Clara ${ }^{4}$ \\ ${ }^{1}$ Department of Physiotherapy, Egas Moniz Higher School of Health, Almada, Portugal \\ ${ }^{2}$ Interdisciplinary Research Centre Egas Moniz, Almada, Portugal \\ ${ }^{3}$ Garcia de Orta Hospital, Almada, Portugal \\ ${ }^{4}$ Faculty of Human Kinetics-Lisbon University, Interdisciplinary Centre for the Study of Human Performance (CIPER), Lisbon, Portugal
}

Email address:

amcfap@gmail.com (A. M. Pereira)

${ }^{*}$ Corresponding author

\section{To cite this article:}

Angela Maria Pereira, Ernesto Pereira, Sónia Vicente, Helena Santa-Clara. Effectiveness of Two Exercise Training Programs in Patients with Chronic Obstructive Pulmonary Disease. American Journal of Internal Medicine. Vol. 9, No. 4, 2021, pp. 160-165. doi: 10.11648/j.ajim.20210904.11

Received: May 30, 2021; Accepted: June 15, 2021; Published: June 23, 2021

\begin{abstract}
This study intended to assess the effectiveness ten years later, after attending to a combined or aerobic exercise training program, in Chronic Obstructive Pulmonary Disease (COPD) patients. Methods: Twenty moderate COPD men, were randomized into two groups: ten patients (age-66.5 5.2 years) to a combined exercise training program (CETG), and ten (age$65.4 \pm 3.6$ years) to an aerobic program (AETG), for $10 \mathrm{~W}, 3 \mathrm{xW}$. Outcome variables included cardiopulmonary function (cardiopulmonary exercise test (CPET) and 6-min-walk-distance (6MWD), muscular strength (1-RM); and quality of life (HRQL) with SF-36 and SGRQ. Ten years later, both groups were compared with ten patients who weren't submitted to exercise programs (CG), evaluating health service recurrence (HSR) and respiratory mortality. Results: Both exercise groups increased $(\mathrm{p}<.05)$ functional capacity $\left(\mathrm{VO}_{2}\right.$ peak: CETG-25 $\pm 18 \%$, AETG-26 $\pm 25 \%$ ); CPET time/power (CETG-42 $\pm 30 \%$, AETG-65 $\pm 47 \%$ ), 6MWD (CETG, 12 $\pm 3 \%$; AETG, 7 $\pm 4 \%$ ) and HRQL immediately after exercise, with greater benefits for the CETG $(\mathrm{p}<.05)$ in all variables. Ten years later, there were no differences between exercise groups on mortality and HSR. Between exercise groups and CG there were only significant differences on HSR. Conclusions: Combined exercise was more effective than aerobic with greater improvement in muscular strength, functional capacity and HRQL. Participation in exercise programs seems to reduce HSR at long-term follow-up.
\end{abstract}

Keywords: COPD, Aerobic Exercise, Strength Exercise, Health Status, Health Service Recurrence

\section{Introduction}

Chronic Obstructive Pulmonary Disease (COPD) is a major cause of chronic morbidity and mortality worldwide with important clinical consequences, such as a decline of health status and quality of life [1-3].

Exercise training is recognized as a fundamental component of respiratory rehabilitation because of its positive effects on muscle function $[2,4]$. Literature shows that aerobic exercise improves exercise performance and decreases dyspnea perception. Aerobic exercise enhances muscle oxidative capacity with muscular function improvement but it has small effect in muscle atrophy and weakness [5].

Resistance training improves muscle strength, endurance, when assessed by the six-minute walk distance (6MWD), and perceived dyspnea in COPD patients. However, it appears to have little effect on $\mathrm{VO}_{2 \max },[3,6,7]$. Evidence suggests that combined exercise (resistance/aerobic) training (CET) provides similar endurance benefits and greater improvements in muscle strength compared to aerobic training alone (AET) [8-9]. Although, for quality of life, studies have shown improvement with resistance training [6], the effects are different between CET and AET, with better results for Health-related Quality of life (HRQL) and dyspnea perception in CET [10]. 
Almost all studies on CET in COPD patients used short term training programs (six to twelve weeks) with a mild to high training intensity $[11,12]$. In Portugal, respiratory rehabilitation usually doesn't include exercise training and treatment of COPD is based in drug therapy and respiratory physiotherapy. Also, most of the hospitals are not prepared to perform exercise in their facilities. Therefore, the first purpose of this study was to assess the effectiveness of a CET program compared to an AET program in outpatients with COPD, using a short term training period with high training intensity, on functional capacity, HRQL, and also, to demonstrate its feasibility outside hospital environment. The second purpose was to compare, ten years later, mortality and hospital recurrence of patients who performed exercise programs with those who were only submitted to medical treatment.

\section{Material and Method}

Twenty adult male with moderate COPD [13] were randomly assigned into two groups: ten patients (age, 66.5 \pm 6.2 years; BMI, $27.7 \pm 4.0 \mathrm{~kg} / \mathrm{m}^{2}$ ) to CET Group (CETG) and ten (age, 65.4 \pm 3.6 years; BMI, $25.3 \pm 3.9 \mathrm{~kg} / \mathrm{m}^{2}$ ) to AET Group (AETG). Both groups trained for 10 weeks, 3 times a week, forty to sixty minutes per session. Subjects' baseline characteristics are shown in Table 1. Training was performed at the municipal sports complex under supervision of physiotherapists and physicians from Garcia de Orta Hospital (GOH). A control group (CG) of ten men with moderate COPD who had criteria to be included in the index exercise program (age, 62.2 \pm 6.2 years; BMI, $24.8 \pm 5.3 \mathrm{~kg} / \mathrm{m}^{2}$; FEV1, $57.8 \pm 10.1 \%$ predicted) was included in the ten years' follow-up evaluation. Despite these men met the inclusion criteria to integrate exercise programs, for personal reasons, they weren't able to participate, and during this period they were treated medically.

To be eligible, subjects needed to accomplish the inclusion criteria as previously described in detail elsewhere [14]. Patients were recruited by checking patient's files from the pulmonary department of $\mathrm{GOH}$, and no changes were made on patient's medical therapy program, along training program.

The study was approved by the GOH Ethics Committee and University Scientific Institutional Review Committee and all subjects provided a written informed consent prior participation.
All patients admitted to exercise groups performed a cardiopulmonary exercise test (CPET), before and after training period, on a cycle ergometer, using the standard hospital protocol (3 minutes of unloaded pedaling, incremental workloads of 10 watts each minute, until fatigue, followed by 3 minutes of rest). CPET was interrupted when subjects reported to be too exhausted or breathless. $\mathrm{VO}_{2 \text { peak }}$, ergometer power, $\mathrm{VCO}_{2}, \mathrm{VE}$, respiratory equivalent, respiratory rate, oxygen saturation $\left(\mathrm{SaO}_{2}\right)$, heart rate $(\mathrm{HR})$, blood pressure (BP) were determined, and the perceived exertion was recorded using Borg's scale. The $\mathrm{HR}_{\text {peak }}$, measured at $\mathrm{VO}_{2 \text { peak }}$, was the main parameter in establishing training intensity for AET.

A 6MWD was performed and $\mathrm{HR}, \mathrm{SaO}_{2}$ and Borg symptom ratings were recorded at rest and immediately after walking cessation [15].

The evaluation protocols used in muscle strength, HRQL and exercise training have been previously described in detail elsewhere [14].

In the ten-year evaluation, data from all patients were gathered from the hospital files and completed by phone interview if there was no information within the last six months', prior the evaluation date. The collected data, included the number of hospitalizations or recurrence to emergency department, owed to respiratory exacerbation, and mortality of respiratory cause.

\section{Statistical Analysis}

Baseline characteristics values are reported as mean values \pm SD. All variables had normal distribution. Comparison among and between groups were performed by Student $t$-tests. Analysis of variance (ANOVA) of repeated measures were used to investigate the effect of the training program (group) and time (pre-post). When significant interaction was observed, $t$-tests were used to determine where interaction occurred. Modification rates were calculated using the equation ((value after-value before)/value before)*100. Clinically significant differences were defined as $-4 \%$ for each Saint George's Respiratory Questionnaire (SGRQ) [16], and +10 points for the SF-36 profiles [17-19]. The level of significance was set at $\alpha=0.05$. SPSS 26 program was used for statistical analysis.

Table 1. Subjects characteristics referring mean value and standard deviation, obstruction degree, height, weight and years of disease; also percent values of professional situation

\begin{tabular}{llc}
\hline & Combined Group (CETG) (n=10) & Aerobic Group (AETG) (n=10) \\
\hline Age & $66.5 \pm 6.2$ & $65.4 \pm 3.6$ \\
$\mathrm{FEV}_{1}(\%$ predicted) & $54.9 \pm 9.9$ & $56.5 \pm 9.3$ \\
$\mathrm{SaO}_{2}$ at rest $(\%)$ & $94.1 \pm 2.3$ & $96.3 \pm 2.1$ \\
$\mathrm{BMI}\left(\mathrm{kg} / \mathrm{m}^{2}\right)$ & $27.7 \pm 4.0$ & $25.3 \pm 3.9$ \\
Years of disease & $7.60 \pm 9.5$ & $7.1 \pm 9.34$ \\
Professional situation & & $87.5 \%$ \\
Retired & $87.5 \%$ & $12.5 \%$ \\
Unemployed & $12.5 \%$ & \\
\hline
\end{tabular}

$\mathrm{SaO}_{2}$ : oxygen saturation; BMI: body mass index; $\mathrm{FEV}_{1}$ : forced expired volume in first second. 


\section{Results}

All results reported for the training exercise groups are based on 15 subjects who completed all tests and training requirements; 5 patients dropped out of the study, 2 from AETG and 3 from CETG for professional reasons, being posteriorly integrated in control group. There were no differences between groups in demographic characteristics as age, height, weight, $\mathrm{FEV}_{1}$, years of disease, or professional activity (Table 1).
ANOVA (Table 2) revealed significant interactions $(\mathrm{p}<0.05)$ between group and time (pre-post training) for $\mathrm{FEV}_{1}$, $\mathrm{VE} / \mathrm{VO}_{2 \text { peak }}$ and $6 \mathrm{MWD}$. There were group differences for $\mathrm{VE} / \mathrm{VO}_{2 \text { peak, }}$, where CETG decreased from $31.2 \pm 9.5$ to $25.9 \pm 7.5$. For 6MWD CETG increased from $480.72 \pm 47.3$ to $538.8 \pm 54.6$ vs an increase from $536.4 \pm 42.8$ to $571.7 \pm 42.3$ for AETG. FEV 1 changed in CETG (55.2 \pm 9.9 to $60.2 \pm 8.4)$ but not in AETG (55.2 \pm 9.1 to 56.1 \pm 8.4 ) (Table 3).

Table 2. P-values from mixed model repeated measures ANOVA: testing the effect of training program, time and their interaction on functional capacity, muscle strength, and quality of life.

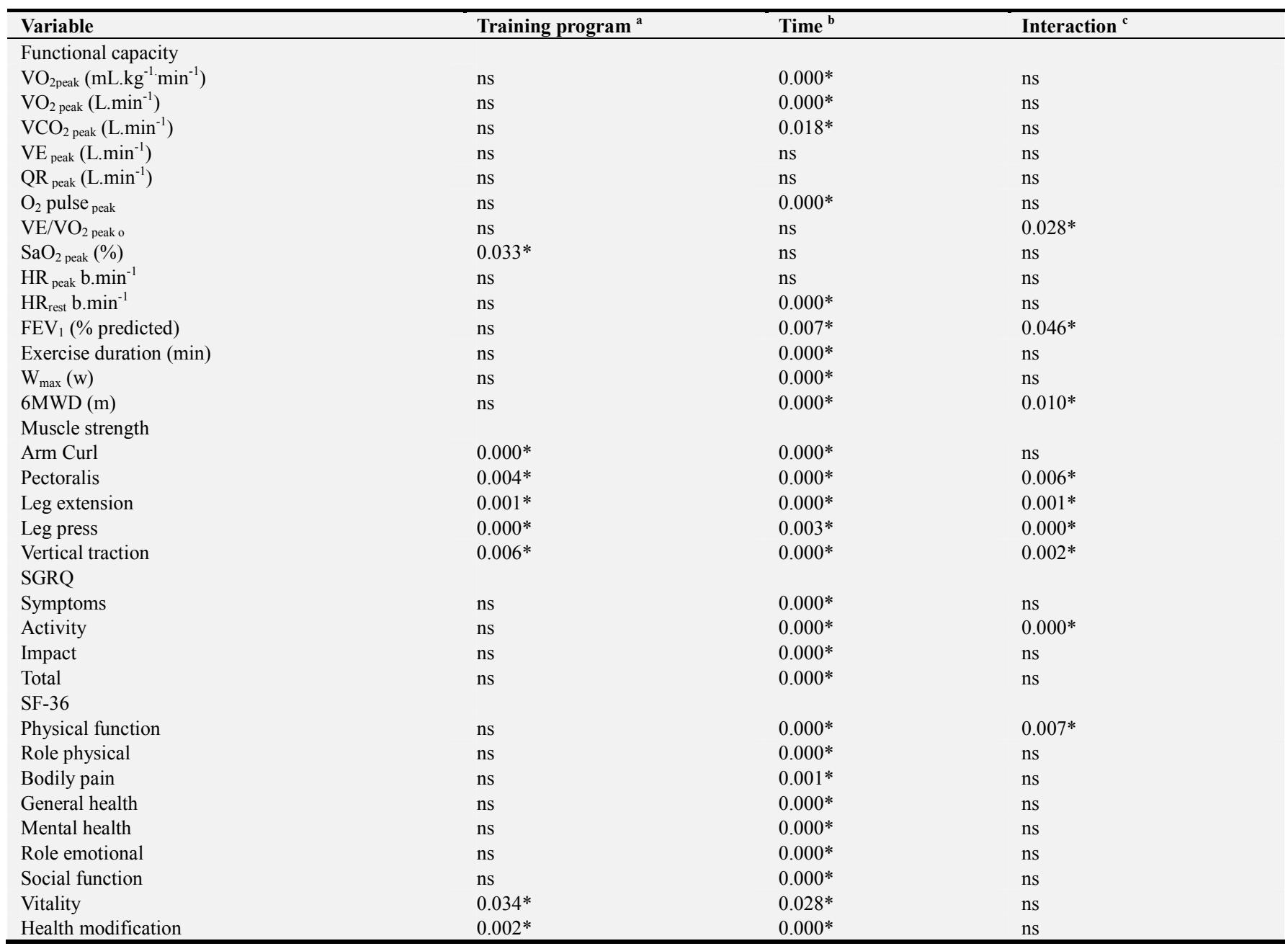

${ }^{*} \mathrm{p}<0.05 ;{ }^{a}$ test of between subjects' effects; ${ }^{\mathrm{b}}$ test of within subjects' effects; ${ }^{\mathrm{c}}$ test of interaction between the independent factor and the repeated measures.

There were no interactions with the other cardiorespiratory variables. The main effects of training (pre-post) were in $\mathrm{VO}_{2 \text { peak }}, \mathrm{O}_{2}$ pulse $\mathrm{peak}_{\text {peak }}, \mathrm{HR}_{\text {rest }}$, exercise duration and $\mathrm{W}_{\max }$, $(\mathrm{p}<0.05)$ (Table 2).

Significant interactions were observed for all strength variables except arm curls (Tables 2 and 4). The $t$-test demonstrated significant differences between groups for these variables with greater improvements shown for CETG.

When analysing HRQL using SGRQ, significant interaction was observed only for the activity dimension, where CETG improved more than AETG, although both groups showed significant improvements. Similarly, data from SF-36 showed a significant interaction in the physical function dimension with greater improvement for CETG. There were main effects for time (pre-post) for all the variables $(\mathrm{p}<0.05)$ and for vitality and health status there was also a main effect on CETG (Table 2).

At ten years' follow-up, significant differences $(p<0.01)$ were observed due to health care recurrence for pulmonary reasons, between patients included in exercise programs and those who were not. Patients who integrated the CETG had nine documented appointments to hospital emergency (HE). 
From those, four were admitted with a total of 37 admission days; for the AETG patients were documented 12 visits to HE, seven admissions with a total of 46 admission days; for the control group were documented 112 visits to $\mathrm{HE}$ and 74 admissions with a total of 567 admission days. A total of seven deaths were observed, one on the CETG, three on the AETG and three on the control group, only the death on CETG was caused by respiratory pathology.

Table 3. Mean and standard deviation values for basal and final values of functional cardiorespiratory parameters, in combined and in aerobic groups.

\begin{tabular}{|c|c|c|c|c|c|c|}
\hline & \multicolumn{3}{|c|}{ Combined Group } & \multicolumn{3}{|c|}{ Aerobic Group } \\
\hline & Before & After & p* & Before & After & p* \\
\hline $\mathrm{VO}_{2 \text { peak }}\left(\mathrm{mL} \cdot \mathrm{kg}^{-1} \mathrm{~min}^{-1}\right)$ & $13.6 \pm 4.6$ & $16.5 \pm 4.3^{*}$ & 0.002 & $15.8 \pm 5.4$ & $18.5 \pm 5.0 *$ & 0.022 \\
\hline $\mathrm{VO}_{2 \text { peak }}\left(\mathrm{L} \cdot \mathrm{min}^{-1}\right)$ & $1.1 \pm 0.39$ & $1.3 \pm 0.4^{*}$ & 0.001 & $1 \pm 0.2$ & $1.2 \pm 0.1 *$ & 0.025 \\
\hline $\mathrm{VCO}_{2 \text { peak }}\left(\mathrm{L} \cdot \mathrm{min}^{-1}\right)$ & $1.00 \pm 0.38$ & $1.13 \pm 0.43$ & ns & $0.98 \pm 0.24$ & $1.18 \pm 0.15^{*}$ & 0.040 \\
\hline $\mathrm{VE}_{\text {peak }}\left(\mathrm{L} \cdot \mathrm{min}^{-1}\right)$ & $33.3 \pm 8.3$ & $33.4 \pm 9.2$ & ns & $30.5 \pm 8.8$ & $36.8 \pm 5.4$ & ns \\
\hline $\mathrm{QR}_{\text {peak }}\left(\mathrm{L} \cdot \mathrm{min}^{-1}\right)$ & $0.86 \pm 0.05$ & $0.87 \pm 0.05$ & ns & $0.94 \pm 0.11$ & $0.91 \pm 0.04$ & ns \\
\hline $\mathrm{VE} / \mathrm{VO}_{2 \text { peak o }}$ & $31.2 \pm 9.4$ & $25.9 \pm 7.5^{* \dagger}$ & 0.020 & $29.2 \pm 6.2$ & $28.6 \pm 5,2$ & ns \\
\hline $\mathrm{SaO}_{2 \text { peak }}(\%)$ & $91.1 \pm 2.6$ & $92 \pm 2.6$ & ns & $95.2 \pm 1.7$ & $94.2 \pm 3.9$ & ns \\
\hline $\mathrm{RR}_{\text {neak }}\left(\mathrm{c} \cdot \mathrm{min}^{-1}\right)$ & $29.38 \pm 6.8$ & $26.50 \pm 5.6$ & ns & $28,14 \pm 5,4$ & $29.6 \pm 4.9$ & ns \\
\hline $\mathrm{HR}_{\text {peak }}\left(\mathrm{b} \cdot \mathrm{min}^{-1}\right)$ & $116.8 \pm 14.5$ & $110.7 \pm 11.0$ & ns & $108,8 \pm 17,8$ & $112.2 \pm 19.5$ & ns \\
\hline $\mathrm{HR}_{\text {reste }}\left(\mathrm{b} \cdot \mathrm{min}^{-1}\right)$ & $67.8 \pm 4.8$ & $64.8 \pm 4.6^{*}$ & 0.000 & $62.8 \pm 7.9$ & $60.2 \pm 9.0 *$ & 0.004 \\
\hline $\mathrm{FEV}_{1}(\%$ predicted $)$ & $55.2 \pm 9.9$ & $60.2 \pm 8.4^{*}$ & 0.020 & $55.2 \pm 9.1$ & $56.1 \pm 8.4$ & ns \\
\hline Exercise duration (min) & $6.8 \pm 2.1$ & $9.2 \pm 2.0 *$ & 0.000 & $6.7 \pm 1.9$ & $8.4 \pm 1.7^{*}$ & 0.003 \\
\hline 6MWD (m) & $480.7 \pm 47.3$ & $538.8 \pm 45.6 *^{\dagger}$ & 0.000 & $536.4 \pm 42.8$ & $571.7 \pm 42.3 *$ & 0.002 \\
\hline
\end{tabular}

$\mathrm{VO}_{2 \text { peak: }}$ maximal oxygen uptake; $\mathrm{VCO}_{2 \text { peak }}$ : carbon dioxide production; $\mathrm{VE}_{\text {peak }}$ : minute ventilation; $\mathrm{QR}_{\text {peak }}$ : respiratory quotient; Pulse $\mathrm{O}_{2 \text { peak}}$ : oxygen pulse; $\mathrm{VE} / \mathrm{VO}_{2 \text { peak }}, \mathrm{VE} / \mathrm{VCO}_{2 \text { peak }}$ : ventilatory equivalents for oxygen uptake and carbon dioxide production; $\mathrm{SaO}_{2}$ : oxygen saturation peak; $\mathrm{HR}_{\mathrm{rest}}$ b.min ${ }^{-1} \mathrm{HR}_{\text {peak }}$ b. $\min ^{-1}$ heart rate at basal and peak stages, $\mathrm{FEV}_{1}$ : forced expired volume in first second; $\mathrm{W}_{\max }$ : maximal work rate; 6MWD: 6-min walk distance.

* Intra-group modifications $\mathrm{p}<0.05 ; \uparrow$ Modifications between groups $\mathrm{p}<0.05$.

Table 4. Mean and standard deviation values for basal, final values and modifications rates from muscular function relatively to muscular groups used in muscular dynamic strength exercises; Arm curl, Pectoralis, Leg extension, Leg press and vertical traction, at the combined group (CETG) and the aerobic group (AETG).

\begin{tabular}{|c|c|c|c|c|c|c|c|c|}
\hline & \multicolumn{3}{|c|}{ Combined Group } & \multicolumn{5}{|c|}{ Aerobic Group } \\
\hline & Before & After & $\Delta \%$ & p* & Before & After & $\Delta \%$ & $p^{*}$ \\
\hline Arm Curl & $37.7 \pm 4.8^{* *}$ & $45 \pm 4.2 *^{\dagger}$ & $20.4 \pm 14.4$ & 0.001 & $26.7 \pm 3.7$ & $29.8 \pm 4.8^{*}$ & $12.0 \pm 10.3$ & 0.021 \\
\hline Bench press & $28.1 \pm 4.5^{* *}$ & $38.2 \pm 5.3 * \dagger$ & $37.3 \pm 15.8$ & 0.011 & $22.2 \pm 4.6$ & $26.7 \pm 5.6^{*}$ & $20.3 \pm 14.3$ & 0.007 \\
\hline Leg extension & $32.5 \pm 2.9 * *$ & $47.7 \pm 4.6 * \dagger$ & $47.8 \pm 17.4$ & 0.000 & $27.5 \pm 4.1$ & $34.4 \pm 6.4 *$ & $24.6 \pm 12.0$ & 0.002 \\
\hline Leg flexion & $123.7 \pm 11.2 * *$ & $169.3 \pm 18.0^{*}{ }^{\dagger}$ & $37.4 \pm 13.8$ & 0.000 & $94.0 \pm 9.2$ & $115.0 \pm 15.5^{*}$ & $21.9 \pm 5.3$ & 0.018 \\
\hline Lat pulldown & $44.25 \pm 6.4 * *$ & $51,0 \pm 7.7 * \dagger$ & $15.2 \pm 5.8$ & 0.000 & $37.5 \pm 3.8$ & $39.1 \pm 3.1$ & $4.5 \pm 5.4$ & ns \\
\hline
\end{tabular}

$\Delta \%$ : Modification rate; * Modifications in group $\mathrm{p}<0.05 ;{ }^{\dagger}$ Modifications between groups $\mathrm{p}<0.05 ; * *$ Initial differences between groups for initials values.

\section{Discussion}

The present study showed that exercise has beneficial effects on functional capacity in subjects with moderate COPD We observed increase in aerobic capacity, shown by the increase in $\mathrm{VO}_{2 \text { peak }}$, and in functional performance, shown by better performance in $6 \mathrm{MWD}$, and in CPET. These findings were similar to those previously reported [3, 7, 12, 20-27]. Cooper [28] showed an increase in $\mathrm{VO}_{2 \text { peak }}$ of $20 \%$ after AET program. Sawyer et al. [10] also showed an increase in $\mathrm{VO}_{2 \text { peak }}$ and $12 \mathrm{MWD}$ after training. An increase in $\mathrm{VO}_{2 \text { peak }}$ can result in a decrease of ventilatory needs at submaximal effort levels, which may lead to an increase in exercise tolerance [29].

As an index of ventilatory efficiency, the $\mathrm{VE} / \mathrm{VO}_{2}$ tends to have lower values in trained subjects, due to a better use of $\mathrm{O}_{2}$ [30], which may explain the lower values found in the CETG. We also observed a decrease in the ventilatory equivalent for $\mathrm{CO}_{2}\left(\mathrm{VE} / \mathrm{VCO}_{2}\right)$ in the CETG, probably due to a decrease in breathing rate, which can indicate an improvement in alveolar ventilation.

Both exercise training programs significantly improved fatigue resistance and endurance, similar to previous studies $[7,12,23,24,31]$. Despite the lesser duration in performing AET it appears that CET provides a greater training stimulus for endurance improvement. We can relate this result with the fact the CETG patients have performed longer distances in the 6MWD. This may also have been related to changes in $\mathrm{FEV}_{1}$ which was a surprising finding, since $F E V_{1}$ had not always been altered in other studies [23, 32].

There was a $10 \%$ improvement in predicted FEV1 associated with an increase of $11 \%$ in FVC in the CETG, suggesting that $\mathrm{CET}$ provides a beneficial effect on pulmonary function which is not evident in AET. Our findings are consistent with Hoff et al. [33] who found a significant increase in $\mathrm{FEV}_{1}$ following eight weeks of high intensity resistance leg training in COPD patients. This improvement can be related to abdominal muscle function improvement as a result of resistance exercise [34]. Considering that $\mathrm{FEV}_{1}$ is a 
strong clinical index of both pulmonary function and COPD disease severity, it appears that CET provides a substantial clinical benefit not evident in AET.

Improvements in maximal muscular strength demonstrate that combined program enhanced muscle function, consistent with results found in previous studies [3, 7, 12, 24, 27, 31]. For CETG, muscle strength had an increased range from $15.2 \%$ for lat pulldown to $47.8 \%$ for leg extension. For AETG, the increased muscle strength range was between $4.5 \%$ for lat pulldown and $24.6 \%$ for leg extension. Similar findings have been reported by Ortega et al. [7]. Even though muscle strength increased more in the CETG, this didn't translate into greater improvement in cardiorespiratory fitness. However, the significantly greater increase in 6MWD for CETG may suggest that there was a greater increase in functional capacity for this kind of training.

Our results showed that health status perception improved for all subjects, which probably reflects beneficial impact of exercise on health status for COPD patients [3, 7, 20-24, 32, 34]. However, physical function improved more in CETG, when assessed by both HRQL questionnaires, which suggests that perceived physical function is probably related to improvement in muscle function, as suggested by others [12]. Thus, adding muscle strength to a clinical rehabilitation program for COPD patients, appear to be clinically useful.

Interestingly, there was no correlation between 6MWD test and health status perception. This finding was similar to that reported by Limsuwat et al. [15], who suggest that SF-36 and 6MWD measure different types of health status. Also Wijkstra et al. [20] suggest that an improvement in exercise tolerance may not be associated with an improvement in HRQL, since this subjective issue may not be influenced by exercise tolerance.

The observational evaluation made ten years after the index exercise program showed a great reduction in hospital readmission for those who participated in the program compared with those who were not included. Although, we couldn't find data supporting these results in literature, a systematic review by Puhan et al. [35] suggests that respiratory physiotherapy is effective in COPD patients after acute exacerbation, in reducing readmissions and consequently associated costs. An economic analysis was not conducted, but it seems that health care costs were reduced, as the admission days were less for patients who performed the exercise programs.

The main limitation of this study was the small number of participants, which influences the generalization of our findings. Another limitation was the lack of a control group from the beginning which was attenuated by its inclusion on the observational comparison at ten years.

\section{Conclusion}

In conclusion, CET appear to be more effective for COPD patients than AET. There were no clinical adverse events during training, which allow us to conclude that performing supervised exercise outside hospital environment is safe for these patients. Also, participation in exercise programs seems to have a positive impact in disease burden and costs, by decreasing long-term health resources recurrence. Resistance exercise training should be considered as a standard part of exercise rehabilitation programs for this population.

Further studies, with larger sample size and costeffectiveness analysis are needed to support the inclusion of exercise programs in management of COPD patients.

\section{Conflict of Interest}

The authors declare that they have no competing interests.

\section{Funding}

This work is financed by national funds through the FCT Foundation for Science and Technology, I. P., under the project UIDB/04585/2020.

\section{Acknowledgements}

Several people and institutions contributed to this study and we would like to express our thanks to them. India Remedios, MD and Martins dos Santos, MD, PhD in Memorium; Almada City Hall; the company Linde Sogás Lda.

\section{References}

[1] Barnes PJ. Cellular and Molecular Mechanisms of Chronic Obstructive Pulmonary Disease. Clinics in Chest Medicine. 2014 Mar; 35 (1): 71-86.

[2] Jaitovich A, Barreiro E. Skeletal Muscle Dysfunction in Chronic Obstructive Pulmonary Disease. What We Know and Can Do for Our Patients. Am J Respir Crit Care Med 2018 Jul; 198 (2): $175-86$.

[3] Storer TW. Exercise in chronic pulmonary disease: resistance exercise prescription. Med Sci Sports Exerc. 2001 Jul; 33 (7 Suppl): S680-92.

[4] Cooper CB. Exercise in chronic pulmonary disease: aerobic exercise prescription. Medicine \& Science in Sports \& Exercise. 2001; 33: S671-S9.

[5] Hikichi M, Mizumura K, Maruoka S, Gon YJJoTD. Pathogenesis of chronic obstructive pulmonary disease (COPD) induced by cigarette smoke. J Thorac Dis. 2019 Oct: S2129-S40.

[6] Rausch-Osthoff A-K, Kohler M, Sievi NA, Clarenbach CF, van Gestel AJR. Association between peripheral muscle strength, exercise performance, and physical activity in daily life in patients with Chronic Obstructive Pulmonary Disease. Multidisciplinary Respiratory Medicine. 2014 Jul; 9 (1): 37.

[7] Ortega F, Toral J, Cejudo P, Villagomez R, Sanchez H, Castillo J, et al. Comparison of effects of strength and endurance training in patients with chronic obstructive pulmonary disease. Am J Respir Crit Care Med. 2002 Sep 1; 166 (5): 669-74.

[8] Liao W-h, Chen J-w, Chen X, Lin L, Yan H-y, Zhou Y-q, et al Impact of Resistance Training in Subjects With COPD: A Systematic Review and Meta-Analysis. Respiratory Care, 2015 May; 60 (8): 1130-45. 
[9] Epsen UW, Jørgensen KJ, Ringbæk T, Hansen H, Skrubbeltrang C, Lange P. A combination of resistance and endurance training increases leg muscle strength in COPD: An evidence-based recommendation based on systematic review with meta-analyses. Chronic Respiratory Disease. 2015 May; 12 (2): 132-45.

[10] Sawyer A, Cavalheri V, Hill K. Effects of high intensity interval training on exercise capacity in people with chronic pulmonary conditions: a narrative review. BMC Sports Med Rehabil. 2020 Mar; 12 (1): 1-10.

[11] Arnold MT, Dolezal BA, Cooper CB. Pulmonary Rehabilitation for Chronic Obstructive Pulmonary Disease: Highly Effective but Often Overlooked. Tuberc Respir Dis (Seoul). 2020 Apr; 83 (4): 257-67.

[12] Barreiro E, Gea J. Respiratory and Limb Muscle Dysfunction in COPD. COPD: Journal of Chronic Obstructive Pulmonary Disease. 2015 Aug; 12 (4): 413-26.

[13] Labaki WW, Rosenberg SR. Chronic Obstructive Pulmonary Disease. Annals of Internal Medicine. 2020 Aug; 173 (3): ITC17-ITC32.

[14] Pereira AM, Santa-Clara H, Pereira E, Simoes S, Remedios I, Cardoso $\mathrm{J}$, et al. Impact of combined exercise on chronic obstructive pulmonary patients' state of health. Rev Port Pneumol. 2010 Sep-Oct; 16 (5): 737-57.

[15] Boueri FM, Bucher-Bartelson BL, Glenn KA, Make BJ. Quality of life measured with a generic instrument (Short Form-36) improves following pulmonary rehabilitation in patients with COPD. Chest. 2001 Jan; 119 (1): 77-84.

[16] Jones PW. Health status measurement in chronic obstructive pulmonary disease. Thorax. 2001; 56 (11): 880-7.

[17] Wyrwich KW, Metz SM, Kroenke K, Tierney WM, Babu AN, Wolinsky FD. Measuring patient and clinician perspectives to evaluate change in health-related quality of life among patients with chronic obstructive pulmonary disease. J Gen Intern Med. 2007 Feb; 22 (2): 161-70.

[18] Wyrwich KW, Tierney WM, Babu AN, Kroenke K, Wolinsky FD. A comparison of clinically important differences in health-related quality of life for patients with chronic lung disease, asthma, or heart disease. Health Serv Res. 2005 Apr; 40 (2): 577-91.

[19] Wyrwich KW, Fihn SD, Tierney WM, Kroenke K, Babu AN, Wolinsky FD. Clinically important changes in health-related quality of life for patients with chronic obstructive pulmonary disease: an expert consensus panel report. J Gen Intern Med. 2003 Mar; 18 (3): 196-202.

[20] Wijkstra PJ, Van Altena R, Kraan J, Otten V, Postma DS, Koeter GH. Quality of life in patients with chronic obstructive pulmonary disease improves after rehabilitation at home. Eur Respir J. 1994 Feb; 7 (2): 269-73.

[21] Beaumont M, Mialon P, Le Ber C, Le Mevel P, Péran L, Meurisse $\mathrm{O}$, et al. Effects of inspiratory muscle training on dyspnoea in severe COPD patients during pulmonary rehabilitation: controlled randomised trial. European Respiratory Journal 2018 Jan; 51 (1): 1701107.

[22] McCarthy B, Casey D, Devane D, Murphy K, Murphy E, Lacasse Y. Pulmonary rehabilitation for chronic obstructive pulmonary disease. Cochrane Database Syst Rev. 2015 Oct;(2): $1-188$.
[23] Parshall MB, Schwartzstein RM, Adams L, Banzett RB, Manning HL, Bourbeau J, et al. An Official American Thoracic Society Statement: Update on the Mechanisms, Assessment, and Management of Dyspnea. Am J Respir Crit Care Med. 2012 Fev; 185 (4): 435-52.

[24] Bernard S, Whittom F, Leblanc P, Jobin J, Belleau R, Berube $\mathrm{C}$, et al. Aerobic and strength training in patients with chronic obstructive pulmonary disease. Am J Respir Crit Care Med. 1999 Mar; 159 (3): 896-901.

[25] Puente-Maestu L, Palange P, Casaburi R, Laveneziana P, Maltais F, Neder JA, et al. Use of exercise testing in the evaluation of interventional efficacy: an official ERS statement. Eur Respir J. 2016 Feb; 47 (2): 429-60.

[26] Rochester CL, Vogiatzis I, Holland AE, Lareau SC, Marciniuk DD, Puhan MA, et al. An Official American Thoracic Society/European Respiratory Society Policy Statement: Enhancing Implementation, Use, and Delivery of Pulmonary Rehabilitation. Am J Respir Crit Care Med. 2015 Dec; 192 (11): 1373-86.

[27] Bolton CE, Bevan-Smith EF, Blakey JD, Crowe P, Elkin SL, Garrod R, et al. British Thoracic Society guideline on pulmonary rehabilitation in adults: accredited by NICE. Thorax. 2013 Sep; 68 (Suppl 2): ii1-ii30.

[28] Cooper CB. Exercise in chronic pulmonary disease: limitations and rehabilitation. Med Sci Sports Exerc. $2001 \mathrm{Jul}$; 33 (7 Suppl): S643-6.

[29] Maltais F, Decramer M, Casaburi R, Barreiro E, Burelle Y, Debigaré R, et al. An Official American Thoracic Society/European Respiratory Society Statement: Update on Limb Muscle Dysfunction in Chronic Obstructive Pulmonary Disease Am J Respir Crit Care Med. 2014 May. 2; 189 (9): e15-e62.

[30] Choudhary SS, Choudhary S. Exercise testing in assessment and management of patients in clinical practice - present situation. Lung India. 2008 Jul; 25 (3): 111-7.

[31] Spruit MA, Singh SJ, Garvey C, ZuWallack R, Nici L, Rochester C, et al. An Official American Thoracic Society/European Respiratory Society Statement: Key Concepts and Advances in Pulmonary Rehabilitation. Am J Respir Crit Care Med. 2013 Oct; 188 (8): e13-e64.

[32] Zwerink M, Brusse-Keizer M, van der Valk P, Zielhuis GA, Monninkhof EM, van der Palen J, et al. Self management for patients with chronic obstructive pulmonary disease. Cochrane Database Syst Rev. 2014 Mar; (3): 1-193.

[33] Hoff J, Tjonna AE, Steinshamn S, Hoydal M, Richardson RS, Helgerud J. Maximal strength training of the legs in COPD: a therapy for mechanical inefficiency. Med Sci Sports Exerc. 2007 Feb; 39 (2): 220-6.

[34] Puente-Maestu L, Sanz ML, Sanz P, Cubillo JM, Mayol J, Casaburi R. Comparison of effects of supervised versus selfmonitored training programmes in patients with chronic obstructive pulmonary disease. Eur Respir J. 2000 Mar; 15 (3): 517-25.

[35] Puhan MA, Gimeno-Santos E, Cates CJ, Troosters T. Pulmonary rehabilitation following exacerbations of chronic obstructive pulmonary disease. Cochrane Database Syst Rev. 2016 Dec; (12): 1-93. 